\title{
Evaluation of the incidence and outcome of gestational diabetes mellitus using the current international consensus guidelines for diagnosing hyperglycaemia in pregnancy
}

\author{
Ganga Sagar Tiwary*, Meenakshi K. Bharadwaj, Manash Biswas, Madhusudan Dey
}

Department of Obstetrics and Gynecology, Armed Medical College, Pune, Maharashtra, India

Received: 21 December 2015

Revised: 13 February 2016

Accepted: 15 February 2016

\section{*Correspondence: \\ Dr. Ganga Sagar Tiwary, \\ E-mail: gs.tiwary@yahoo.com}

Copyright: () the author(s), publisher and licensee Medip Academy. This is an open-access article distributed under the terms of the Creative Commons Attribution Non-Commercial License, which permits unrestricted non-commercial use, distribution, and reproduction in any medium, provided the original work is properly cited.

\begin{abstract}
Background: GDM is defined as carbohydrate intolerance of variable severity with onset or first recognition during pregnancy. It may be appropriate to screen pregnant women belonging to high-risk populations during the first trimester of pregnancy in order to detect previously undiagnosed Diabetes Mellitus. Formal systematic testing for Gestational Diabetes is usually done between 24 to 28 weeks of gestation. Even though there are many diagnostic criteria and guidelines for management of GDM, there still exists lack of consensus regarding diagnosis and management of patients with GDM. After HAPO study, IADPSG has formulated a new consensus guideline for diagnosing hyperglycaemia in pregnancy which has formed the back bone for this particular study.

Methods: This prospective observational study was carried out for a period of one year from July 2014 to Jun 2015 at AFMC, Pune in Dept. of Obstetrics \& Gynaecology. To determine if gestational diabetes is present in pregnant women, a standard OGTT was performed with $75 \mathrm{~g}$ glucose. The incidence of GDM in antenatal population visiting AFMC, Pune was calculated. Maternal and neonatal outcome was observed and was compared with those of euglycaemic antenatal population.

Results: The incidence of GDM in the antenatal population visiting AFMC, Pune was found to be $12.4 \%$. Family history of Diabetes among first degree relatives is the commonest risk factor associated with GDM. It was found that, with adequate glycaemic control, most of the maternal as well as neonatal complications associated with GDM can be reduced to a level comparable with euglycaemic antenatal population.

Conclusions: The new international consensus guideline in diagnosing GDM has shown an incidence of GDM comparable with other criteria for diagnosing GDM. Ensuring an adequate glycaemic control throughout the antenatal period alleviates most of the maternal and neonatal complications associated with GDM.
\end{abstract}

Keywords: GDM, OGTT, NGT, IADPSG, HAPO, Incidence, Glycemic control, Maternal and neonatal outcome

\section{INTRODUCTION}

GDM is defined as carbohydrate intolerance of variable severity with onset or first recognition during pregnancy. ${ }^{1}$ It can be that the onset of this condition in a pregnancy might indicate a previously undiagnosed type 2 Diabetes Mellitus, or it might be GDM which may resolve spontaneously after delivery. Individuals at high risk for GDM include older women, those with previous history of glucose intolerance, those with a history of large for gestational age babies, women from certain high-risk ethnic groups, and any pregnant woman who has elevated fasting, or random blood glucose levels. ${ }^{2}$ It may be appropriate to screen pregnant women belonging to highrisk populations during the first trimester of pregnancy in order to detect previously undiagnosed Diabetes Mellitus. Formal systematic testing for Gestational Diabetes is usually done between 24 to 28 weeks of gestation. ${ }^{3}$ 
Even though there are many diagnostic criteria and guidelines for management of GDM, there still exists lack of consensus regarding diagnosis and management of patients with GDM. After Hyperglycaemia and Adverse Pregnancy Outcome study, International Association of Diabetes in Pregnancy Study Group has formulated a new consensus guideline for diagnosing hyperglycaemia in pregnancy which has formed the back bone for this particular study. ${ }^{4}$

\section{METHODS}

\section{Source of data}

This prospective observational study was carried out for a period of one year from July 2014 to June 2015 at tertiary care centre in Dept. of Obstetrics \& Gynecology. To determine if gestational diabetes is present in pregnant women, a standard OGTT was performed after overnight fasting (8-14 hours) by giving $75 \mathrm{~g}$ anhydrous glucose in 250-300 ml water. Plasma glucose was measured fasting, after 1 hour and after 2 hours. Pregnant women who met revised IADPSG criteria for diabetes mellitus were classified as having GDM and others who had normal OGTT result were classified as Normal Glucose Tolerant (NGT).

Table 1: Current international consensus guideline for diagnosing GDM. ${ }^{5}$

\begin{tabular}{|ll|}
\hline & Blood Glucose Level (mg/dl) \\
\hline Fasting & 92 \\
\hline 1 hour & 180 \\
\hline 2 hour & 153 \\
\hline
\end{tabular}

\section{Interpretation}

One or more of these values must be equalled or exceeded for diagnosing GDM.

\section{Method of collection of data}

All antenatal patients except those who had pre existing Diabetes or overt diabetes were screened for GDM at 2428 weeks period of gestation. As per the institutional policy, every patient was advised 75g OGTT at 24-28 weeks period of gestation. Patient with risk factor for GDM underwent 75 gm OGTT at first visit only. Patient who had normal OGTT result in the first visit definitely underwent a $75 \mathrm{~g}$ OGTT between 24-28 weeks period of Gestation. A risk assessment for development of GDM was done at the initial antenatal visit.

This high-risk group comprises women who ${ }^{6}$

- $\quad$ are $>35$ years of age

- have pre-pregnancy BMI $>30 \mathrm{~kg} / \mathrm{m}^{2}$

- have family history (i.e., first-degree relative) of diabetes

- have previous h/o GDM
- have previous history of macrosomic baby

- have previous history of unexplained IUFD

All patients who were diagnosed to have GDM were advised to take Medical Nutritional Therapy. ${ }^{7}$ The total per day Calorie requirement was calculated for each patient of GDM according to her pre-pregnancy BMI and present body weight as follows: ${ }^{8}$

a) If the woman had a pre-pregnancy BMI of $>30$ $\mathrm{kg} / \mathrm{m}^{2}$, the total Calorie requirement is 20 $\mathrm{kcal} / \mathrm{kg} /$ day.

b) If pre-pregnancy BMI is between 21 to 29 , it is $25 \mathrm{kcal} / \mathrm{kg} / \mathrm{day}$

c) For pre-pregnancy BMI $<20 \mathrm{~kg} / \mathrm{m}^{2}$, it is 20 $\mathrm{kcal} / \mathrm{kg} / \mathrm{day}$

An additional $100 \mathrm{kcal}$ is added for each trimester to the above obtained value. Total calories consumed were calculated every day and dietary modification, if any, was advised to the patient. After three days of MNT, all patients underwent Six Point Plasma Glucose Profile which included Fasting, post prandial, before lunch, after lunch, before dinner \& after dinner plasma glucose measurement. All post meal samples were collected after 2hrs of major meal. Patients with deranged Plasma Glucose Profile with three or more abnormal values with no pre-meal value exceeding $105 \mathrm{mg} / \mathrm{dl}$ were considered for therapy with oral hypoglycaemic agents. ${ }^{9}$ The drug used was Tab Metformin in a dosage starting from 500 $\mathrm{mg}$ twice daily to a maximum of $2 \mathrm{~g} /$ day. Patients with deranged Plasma Glucose Profile who didn't meet criteria for Oral Hypoglycemic Therapy were treated with Insulin Human Mixtard. The requirement of Insulin for a patient was calculated as $0.7 / 0.8 / 0.9$ units $/ \mathrm{kg}$ body wt. in $1^{\text {st }} / 2^{\text {nd }} / 3^{\text {rd }}$ trimester respectively. Only $2 / 3^{\text {rd }}$ of the above calculated dose was administered, of which $2 / 3^{\text {rd }}$ was administered in the morning and $1 / 3^{\text {rd }}$ in the evening. All patients on Insulin Therapy underwent a Seven Point Plasma Glucose Profile, which included a 2 am value, after at least three days on Insulin. Dose adjustments and titration of Insulin dosage was done as per the laid down criteria. Even after starting Insulin, patients continued to be on MNT. ${ }^{10}$

\section{Surveillance $^{11}$}

The patients who were hospitalized were discharged after achieving a satisfactory glycaemic control, while those who were managed on out-patient basis were hospitalized for supervised MNT, in case of a deranged profile. All patients followed a surveillance plan as follows:

a) MNT/OHA/Insulin therapy as advised

b) Plasma Glucose Profile every 3-4 weekly. More frequent profiles may be asked for depending on the glycaemic control.

c) Anomaly scan between 18 -20 weeks

d) Ultrasonography for fetal growth parameters every 3 weekly after 28 weeks. 
e) Fetal echocardiography at 32 weeks

f) Weekly NST \& AFI after 32weeks.

All parturient with GDM were monitored as per guidelines for Labour Monitoring in high risk pregnancy. A Glycaemic control was followed and Plain Insulin was administered as per sliding scale with a 2 hrly capillary glucose monitoring. All neonates of GDM mothers were closely observed for development of Respiratory Distress, Hypoglycaemia or Seizures during first $24 \mathrm{hrs}$ of birth. Capillary glucose was measured every 3 hrly. A Glucose level less than $40 \mathrm{mg} / \mathrm{dl}$ was considered as Hypoglycaemia. Every neonate was observed for appearance of jaundice and phototherapy was implemented as per advice of Paediatric team. All patients who had Vaginal Delivery were allowed to have normal diet and Plasma Glucose, Fasting \& Post Prandial were measured on the first Post natal day. In case of caesarian delivery, capillary glucose was monitored $4 \mathrm{hrly}$ for the first $24 \mathrm{hrs}$ post partum along with insulin sliding scale and plasma glucose Fasting and Post Prandial were measured once the patient started taking normal diet, usually after $48 \mathrm{hrs}$ of surgery. If the values were within normal range (Fasting <126 mg/dl / Post Prandial <200 $\mathrm{mg} / \mathrm{dl}$ ), the patient continued on normal diet. In case of abnormal plasma glucose values, the patient continued on diet modification or oral hypoglycaemics or Insulin.

All GDM patients were advised to undergo an OGTT with $75 \mathrm{~g}$ Glucose at $6 \mathrm{wks}$ post partum and were termed as either Diabetic or Non-diabetic.

\section{Statistical analysis}

Statistical analysis was carried out by using SPSS version 19 and data has been statistically analysed with Chisquare technique to find the associations between factors. Also Associated $\mathrm{P}$ values were calculated assuming significance at $\mathrm{p}$ value $<0.05 \&$ Confidence Interval Used $(\mathrm{CI})=95 \%$.

\section{RESULTS}

Out of 131 patients who were detected to have GDM, 86 patients $(65.6 \%)$ had only elevated fasting glucose; 15 patients $(11.4 \%)$ had $2 \mathrm{hr}$ value abnormal and 7 patients (5.3\%) had all three values abnormal. Patients with elevated Fasting Plasma Glucose constitute a majority of GDM patients in the antenatal population studied.

Out of the 131 patients detected to have GDM, 33 were amongst the high risk group. This amounts to $40.47 \%$ of the GDM population. Out of the 81 patients who had high risk factor for GDM, 37 had family history of Diabetes out of which 20 were detected to have GDM. Thus, family history of Diabetes among first degree relatives was found to have the commonest association with the development of GDM after history of GDM in previous pregnancy in study population as plotted in Figure 1.

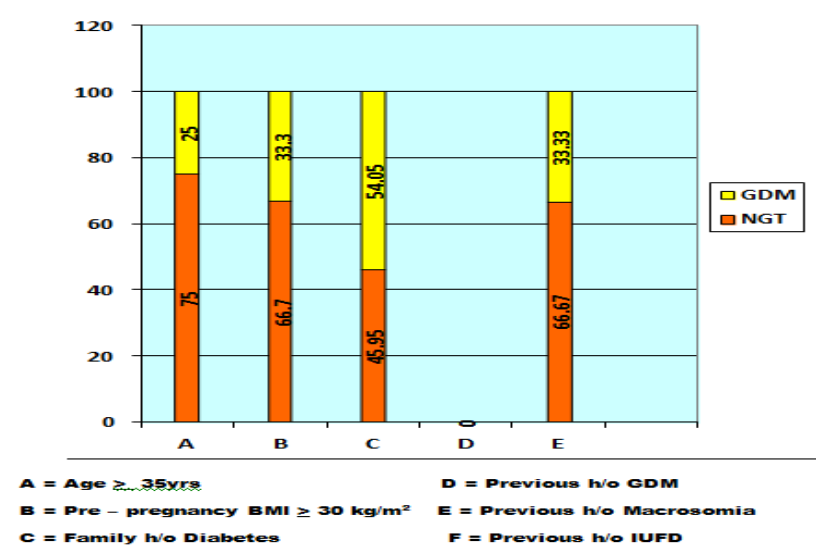

Figure 1: Incidence of GDM in high risk groups.

Table 2: Analysis of $75 \mathrm{~g}$ OGTT result in GDM group.

\begin{tabular}{|lll|}
\hline GDM Group & $\begin{array}{c}\text { Number } \\
\text { of patients }\end{array}$ & Percentage \\
\hline Total GDM Patients & 131 & $12.4 \%$ \\
\hline Only FPG elevated & 86 & $65.6 \%$ \\
\hline All three values elevated & 7 & $5.3 \%$ \\
\hline $\begin{array}{l}\text { Both FPG \& 1hr values } \\
\text { elevated }\end{array}$ & 6 & $4.5 \%$ \\
\hline Only $1 \mathrm{hr}$ value elevated & 9 & $6.8 \%$ \\
\hline Only $2 \mathrm{hr}$ value elevated & 15 & $11.4 \%$ \\
\hline $\begin{array}{l}\text { Both FPG \& 2hr values } \\
\text { elevated }\end{array}$ & 7 & $5.3 \%$ \\
\hline Both $1 \mathrm{hr} \& 2 \mathrm{hr}$ values elevated & 1 & $0.7 \%$ \\
\hline Total & 1056 & \\
\hline
\end{tabular}

Table 3: Association of risk factors with GDM.

\begin{tabular}{|c|c|c|c|}
\hline Factors & GDM & NGT & P-Value \\
\hline $\begin{array}{l}\text { Family history of DM } \\
\text { present }\end{array}$ & 20 & 17 & \multirow[b]{2}{*}{0.000} \\
\hline $\begin{array}{l}\text { Family history of DM } \\
\text { absent }\end{array}$ & 111 & 908 & \\
\hline $\begin{array}{l}\text { H/O Macrosomia } \\
\text { present }\end{array}$ & 0 & 0 & \multirow[b]{2}{*}{-} \\
\hline $\begin{array}{l}\text { H/O Macrosomia } \\
\text { absent }\end{array}$ & 131 & 925 & \\
\hline $\begin{array}{l}\text { H/o GDM in previous } \\
\text { pregnancy present }\end{array}$ & 6 & 4 & \multirow[b]{2}{*}{0.000} \\
\hline $\begin{array}{l}\text { H/o GDM in previous } \\
\text { pregnancy absent }\end{array}$ & 125 & 921 & \\
\hline H/O IUFD present & 2 & 4 & \multirow[b]{2}{*}{0.164} \\
\hline H/O IUFD absent & 129 & 921 & \\
\hline Age $>35$ yrs & 4 & 12 & \multirow[b]{2}{*}{0.126} \\
\hline Age $<35$ yrs & 127 & 913 & \\
\hline $\mathrm{BMI}>30 \mathrm{Kg} / \mathrm{m}^{2}$ & 4 & 8 & \multirow[b]{2}{*}{0.051} \\
\hline $\mathrm{BMI}<30 \mathrm{Kg} / \mathrm{m}^{2}$ & 127 & 917 & \\
\hline
\end{tabular}

There were 81 antenatal patients who had at least one of the high risk factors mentioned above, family history of 
diabetes being the commonest. There was $60 \%$ incidence reported in those patients who had GDM in the previous pregnancy. The incidence of GDM in those patients who have a family history of Diabetes Mellitus among first degree relatives was found to be $54.05 \%$.

The incidence of GDM in those patients who had a previous history of unexplained IUFD was found to be $33.33 \%$. There was a $33.33 \%$ incidence of GDM found in those patients who had BMI $>30 \mathrm{~kg} / \mathrm{m}^{2}$.

Age more than 35 yrs was studied as a high risk for development of GDM. However, it was found in the study that patients with advanced maternal age have an incidence of $25 \%$. Significant association was found among family history of DM, BMI $\geq 30 \mathrm{~kg} / \mathrm{m}^{2}$, previous obstetric history of GDM and development of GDM in the study population.

Obstetric outcome in each GDM patient was analysed and was compared with that of NGT patients as plotted in Figure 2. Obstetric outcome was evaluated under the events such as LSCS/Instrumental delivery for Dystocia, and IUFD. In the study, it was found that almost all adverse obstetric outcomes due to GDM were decreased to a level comparable with that of the NGT group.

Table 4: Analysis of obstetric outcome.

\begin{tabular}{|lcccccc|}
\hline Category & $\begin{array}{l}\text { Total } \\
\text { delivery }\end{array}$ & $\begin{array}{c}\text { Total } \\
\text { LSCS }\end{array}$ & $\begin{array}{c}\text { LSCS for } \\
\text { dystocia }\end{array}$ & $\begin{array}{c}\text { \% of LSCS for Dystocia } \\
\text { among total deliveries }\end{array}$ & $\begin{array}{l}\text { Instrumental } \\
\text { delivery for dystocia }\end{array}$ & $\begin{array}{l}\text { Unexplained } \\
\text { IUFD }\end{array}$ \\
\hline Total (A) & 1056 & 289 & 96 & $9.09 \%$ & 26 & 2 \\
\hline GDM (B) & 131 & 53 & 17 & $12.98 \%$ & 3 & 0 \\
\hline NGT (C) & 925 & 236 & 79 & $8.54 \%$ & 23 & 2 \\
\hline
\end{tabular}

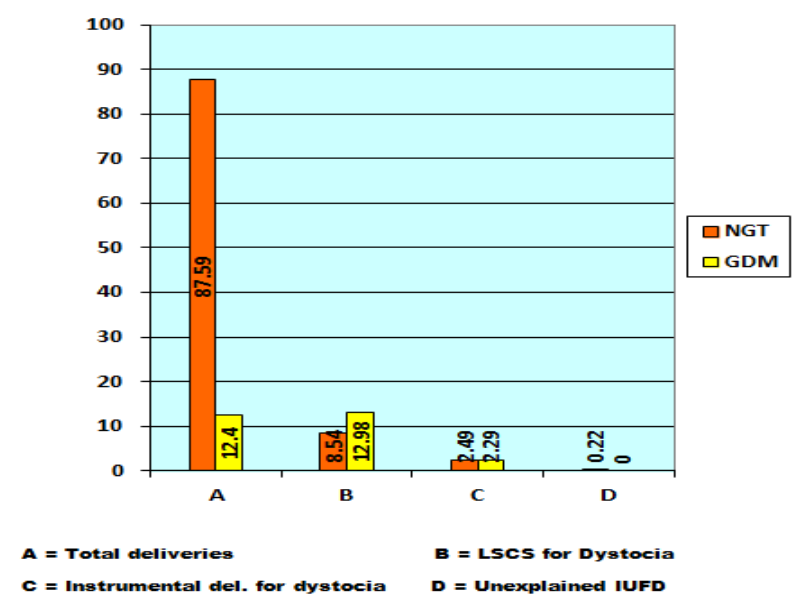

Figure 2: Comparison of obstetric outcome between GDM and NGT.

In our study, it was found that neonatal complications associated with GDM like macrosomia, hypoglycaemia, hyperbilirubinaemia and RDS were reduced to a level comparable to those of euglycaemic group as plotted in Figure 3. It was concluded that good glycaemic control in the antenatal period in GDM prevents macrosomia and other neonatal complications.

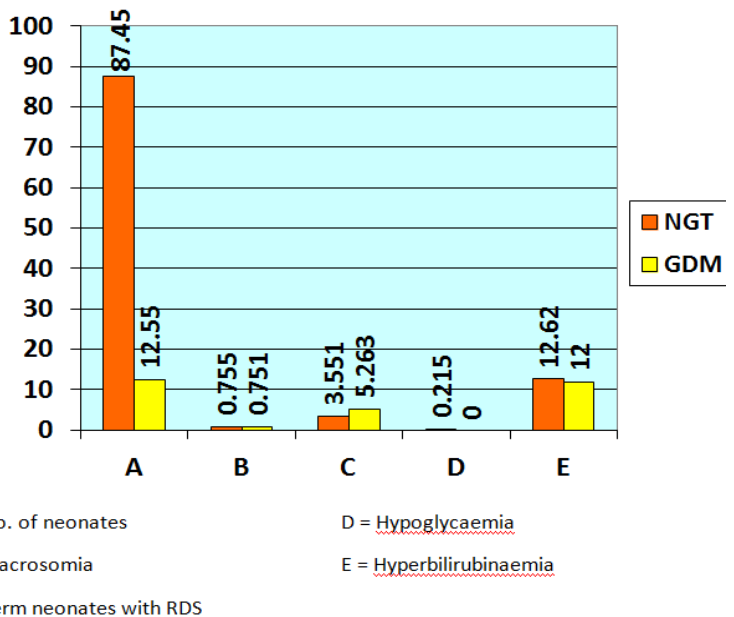

Figure 3: Neonatal complications associated with GDM.

Table 5: Analysis of neonatal outcome.

\begin{tabular}{|llllll|}
\hline & $\begin{array}{l}\text { Total } \\
\text { Neonates }\end{array}$ & Macrosomia & $\begin{array}{l}\text { Term Neonates } \\
\text { with RDS }\end{array}$ & Hypoglycaemia & Hyperbilirubinaemia \\
\hline Total Neonates (A) & $1060 *$ & 8 & 40 & 2 & 133 \\
\hline GDM (B) & 133 & 1 & 7 & 0 & 16 \\
\hline Percentage Bx100 A & $12.55 \%$ & $12.50 \%$ & $17.5 \%$ & 0 & $12.03 \%$ \\
\hline NGT (C) & 927 & 7 & 33 & 2 & 117 \\
\hline
\end{tabular}

$*$ Total Stillbirths $=2$, Twins $=4$ 


\section{DISCUSSION}

\section{Incidence of GDM}

In our study, the incidence of gestational diabetes was found to be $12.4 \%$. The criterion used in our study was the new international consensus guideline as recommended by IADPSG. As evident from other studies, it was found that there is no substantial difference in the frequency of GDM compared to other criteria for diagnosis of GDM. Also in the study, it was found that a majority of GDM patients had only elevated FPG in OGTT. This group accounted for $65.6 \%$ of the GDM population.

\section{Incidence of GDM in high risk population}

In our study, a $40 \%$ association was found between high risk and development of GDM. Also, it was found that previous history of GDM has a significant association for development of GDM in subsequent pregnancies. Family history of GDM was found to be the next most common predictor for GDM.

In a study conducted in Portugal by Detch JC, et al for determining the markers for diagnosis of GDM, it was found that risk factor was associated with $95 \%$ of the GDM population. ${ }^{12}$ The most relevant risk factor was found to be previous history of GDM. Risk factors were found to be very sensitive in GDM detection and provision of family history of Diabetes Mellitus strengthens its relationship with Type 2 Diabetes.

\section{Obstetric outcome}

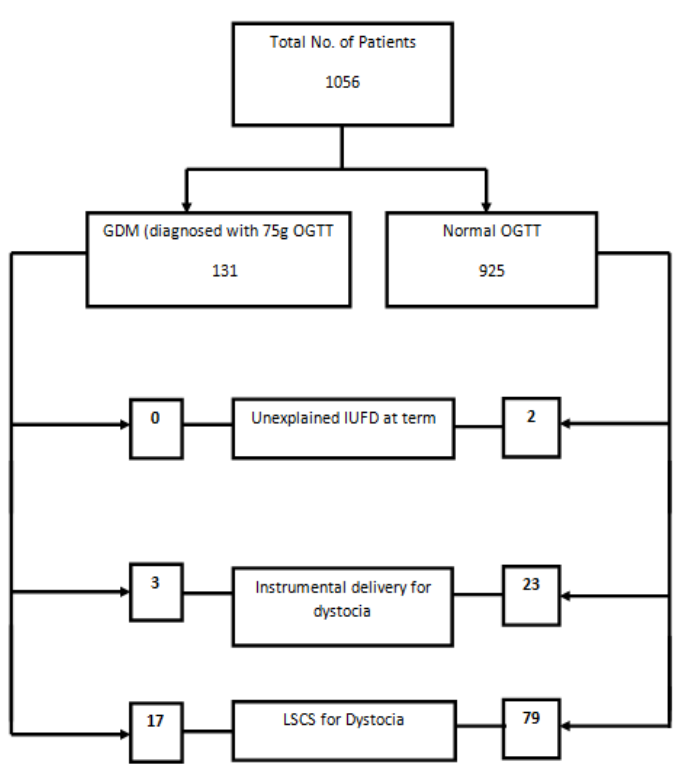

Figure 4: Flow chart depicting obstetric outcome in GDM \& NGT group.

In our study as shown in Figure 4, it was found that all the late pregnancy and perinatal complications like macrosomia, IUFD, birth injuries, dystocia etc are alleviated by maintaining an adequate glycaemic control in the antenatal period. Kwik et al in their study compared the obstetric outcome in treated and untreated GDM. ${ }^{13}$ They found that obstetric outcome is affected by glucose intolerance. In the untreated GDM group there were more macrosomia, more number of caesarian sections or instrumental deliveries for dystocia and birth injuries. In the treated group, the outcome was comparable to euglycaemic population.

\section{Neonatal outcome}

In our study as shown in Figure 5, it was found that neonatal complications associated with GDM like macrosomia, hypoglycaemia, hyperbilirubinaemia and RDS were reduced to a level comparable to those of euglycaemic group. In fact, there were 2 neonates who had hypoglycaemia in the NGT group and none in GDM group. One of the neonates had macrosomia in GDM group and seven in NGT group. RDS requiring NICU admission was studied as a neonatal outcome and it was found that comparatively lesser number of neonates of GDM mothers suffered from RDS. It was concluded that good glycaemic control in the antenatal period in GDM prevents macrosomia and other neonatal complications.

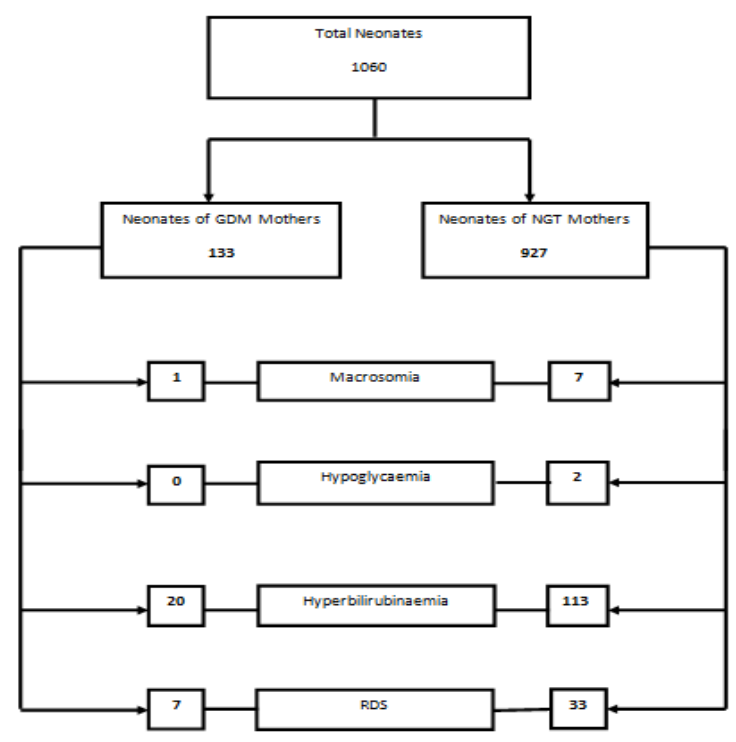

Figure 5: Flow chart depicting neonatal outcome in GDM \& NGT group.

\section{CONCLUSIONS}

The incidence of GDM in the antenatal population visiting Antenatal OPD at Tertiary Care Centre is $12.4 \%$. This incidence of GDM is similar as with new international consensus guideline for diagnosing GDM as compared to other existing criteria for diagnosing hyperglycaemia in pregnancy in the study population. There is a very high association between risk factors for developing GDM and development of GDM in on going 
pregnancy in the study population. Previous history of GDM is the most significant high risk factor associated with GDM followed by family history of Diabetes.

Adequate glycaemic control in the antenatal period alleviates most of the maternal as well as fetal complications associated with GDM. The incidence of dystocia requiring instrumental delivery or Caesarian was found to be the same as that of euglycaemic patients in the study population. Neonatal complications like macrosomia, RDS, hypoglycemia and neonatal jaundice are decreased to a normal level. Unexplained IUFD at term was not reported in the study group.

Medical Nutritional Therapy is highly effective in the management of GDM. Only 5\% of GDM patients required Insulin Therapy. With adequate glycaemic control, all late pregnancy complications and neonatal complications can be alleviated.

Funding: No funding sources

Conflict of interest: None declared

Ethical approval: The study was approved by the Institutional Ethics Committee

\section{REFERENCES}

1. American Diabetes Association Diagnosis and classification of diabetes mellitus (Position Statement). Diabetes Care. 2009;32(1):S62-7.

2. Metzger BE, Coustan DR. Summary and Recommendations of the Fourth International workshop-Conference on Gestational Diabetes Mellitus. Diabetes Care. 1998;21(2):B161-7.

3. International Association of diabetes and Pregnancy Study Groups (IADPSG) recommendations on the diagnosis and classification of Hyperglycemia in pregnancy. IADPSG consensus panel. Diabetes care. 2010;33:676-82.

4. Metzger BE, Gabbe SG, Perrson B. IADPSG recommendations on diagnosis and classification of hyperglycemia in pregnancy. IADPSG Study group panel. Diabetes Care. 2010;33:676-82.

5. HAPO Study Cooperative Research Group The Hyperglycemia and Adverse Pregnancy Outcome (HAPO) Study. Intl J Gynaecol Obstet. 2002;78:6977.

6. American Diabetes Association. Standards of medical care in diabetes. Diabetes Care. 2015;38(1):S1-S93.

7. Divakar H, Tyagi S, Hosmani P. Diagnostic criteria influence prevalence rates for gestational diabetes: implications for interventions in an Indian pregnant population. Perinatology. 2008:10(6);155-61.

8. American college of Obstetrics and Gynecology. Gestational Diabetes. Pratice Bulletin no. 30. Obstet Gynecol. 2001;98:525-38.

9. Jakubowicz DJ, Iuorno MJ, Jakubowicz S, Roberts KA, Nestler JE. Effects of metformin on early pregnancy loss in the polycystic ovary syndrome. $\mathrm{J}$ Clin Endocrinol Metab. 2002;87(2):524-9.

10. Jovanovic L, Ilic S, Pettitt DJ, Hugo K, Gutierrez M, Bowsher RR, et al. Metabolic and immunologic effects of insulin lispro in gestational diabetes. Diabetes care. 1999;22:1422-7.

11. Kjos SL, Leung A, Henry OA, Victor MR, Paul RH. Antepartum surveillance in diabetic pregnancies: Predictors of fetal distress in labor. Am J Obstet Gynecol. 1995;173:1532-9.

12. Detch JC, Almeida AC, Bortolini LG. Markers for diagnosis and treatment in 924 pregnancies with GDM. J Arq Bras Endocrinol Metabol. 2011;55(6):389-98.

13. Kwik M, Secho SK, Smith C. Outcome of pregnancies affected by Impaired Glucose Tolerance. J Diabetes Res Clin Pract. 2007:77(2):263-8.

Cite this article as: Tiwary GS, Bharadwaj MK, Biswas M, Dey M. Evaluation of the incidence and outcome of gestational diabetes mellitus using the current international consensus guidelines for diagnosing hyperglycaemia in pregnancy. Int $\mathbf{J}$ Reprod Contracept Obstet Gynecol 2016;5:663-8. 